\title{
ACTUALIDAD PEDIATRICA.
}

\section{SOBRE REINFECCIONES EXOGENAS $Y$ TUBERCULOSIS DE REINFECCION}

Resumen de los trabajos de Ameuille, Sáenz y Canetti (Presse Méjicale, 11 Junio, 1940), de Bezançon: (Presse Médicale, 16 Nov., 1940), de E. Sergent (Presse Médicale, 30 de Nov., 1940), de Rist (Presse Médicale, 17 Septiembre, 1940).

Los autores analizan las ideas comunmente aceptadas hasta hoy dia sobre la alergia y el mecanismo de la reinfección. Se ha aceptado, dicen, como una vendad indiscutible que todo individuo infectado por el bacilo de Koch mantiene su estado de alergia por toda la vida. Esta alergia se mantedría gracias a un foco tuburculoso más o menos activo en alguna parte del organismo. Este concepto está basado en las investigaciones de Loomis. Pizzini y Lidia Rabinowitsch que demostraron la presencia de bacilos virulentos en al $50 \%$ de gan glios mediastinicos tuberculosos en diferentes etapas de su evolución, obtenidos de individuos adultos muertos de enfermedades tuberculosas. Estas mismas investigaciones ban servido a Behring para establecer que ta tuberculosis de primo-infección da origen a una inmunidad específica que protege el organismo contra nuevas infecciones exógenas. Según Behring. todas las manifestaciones de la enfermedad tuberculosa que sobrevienen en individuos ya tuberculizados tienen que ser de origen endógeno: es la inmunidad para las sobreinfecciones. En estas ideas están basadas una serie de principios de carácter epidemiológico y profiláctico como la vacunación por el $\mathrm{B}$. C. $G$. la convivencia de enfermos con distintos tipos de tuberculosos, etc.

La tuberculosis de reinfección se haría, según las ideas actualmente aceptadas, a partir de procesos cicatriciales (restos de siembras hematógenas), localizados principalmente en los vérticzs. Estas cicatrices que ya fueron descritas por Laennec Naegelli, Brouardel, etc., mantendrían englobados gèrmenes 
viruléntos al estado latente durante un tiempo más o menos largo. De esta manera el organismo mantendría su alergia. con algunas variaciones, por toda la vida. La enfermedad. tuberculosa apareceria con motivo de una atenuación o desaparición de la alergía a causa de debilitamiento orgánico o enfermedades intercurrentes. De este modo queda aceptado el origen endógeno de la mayor parte de las formas do tuberculosis de reinfección: su origen exógeno sólo se acepta en casos de contagios masivos o como detrrminante de una infección endógena.

Las nuevas investigaciones de autotes alemanes como Bräuning y de franceses como Ameuille, Sáenz y Canatt tianden a demostrar que las cicatrices palmonares no siempre corresponden a la primo-infección. Sabemos, desde los trabajos de Küss y de Ghon que el chancro de inoculación es úni. co en un $90 \%$ de los casos y que va acompañado de una adenopatía satélite. Pues bien, en las autópsias de adultos. practicadas por estos autores, sa encuentran, además de las le siones ya calcificadas del complejo primatio cicatrices pulmonares en zonas que corresponden a ganglios sanos. Estas ci catrices se sitúan de preferencia en los vértices pulmonares, sitio en que se locoliza raramente el foco primario. Tienen de característico estas lesiones de ser muy pequeñas (cabeza da alfiler. lenteja) y de no acompañarse jamás de compromiso ganglionar.

Los autores han comprobado que un 65 \% de los adultos tienen cicatrices de esta naturaleza. Ahora bien, en qué momento abarecen estas lesiones? Según las estadísticas de Böhne y de Schürmann basadas en autópsias practicadas en individuos de toda edad se llega a los siguientes resultados: por debajo de los 20 años no hay cicatrices: de 21 a 30 años hay un $1.6 \%$; de 31 a 40 años, un $16 \%$ : de 41 a 50 años. $52 \%$ de 51 a 60 años, $58 \%$ : de 61 a 70 años, $68 \%$; por encima de esta edad, la proporción alcanza a un $95 \%$. Estas misma cifras han sido obtenidas por Ameuille, Sáenz y Canetti. Como vemos, estas cicatrices aumentan extraordinariamente con la edad. Aun más, se ba nodido comprobar. en estas autopsias, lesiones recientes, caseosas, en individuos de edad avanzada (hasta $45 \%$, a los 60 años). De esta manera se puede establecer que aún en los inilividuos de edad ayanzada se encuentran formas de reinfección recientes. Respecto al número de episodios de rein'fecciones, no podemos precisarlo, porque estas lesiones se reabsorven tápidamente $y$ 
porque suelen tener un tamaño tan pequeño ole es difícil encontràrlas, aún a la autopsia. El diagnóstico radiológico de estas cicatrices es sumamente difícil, tanto por su tamaño como por su ubicación. Pueden servir como un medio de comparación los estudios anatómicos y radiológicos practicajos en relación con el chancro primario: asi mientras que el chancro calcificado se comprueba anatómicamente en un 80 a $90 \%$ de los aduitos, no se observa radiológicamente más que en un 10 a $30 \%$ de los casos. Es de advertir, por otra parts, rue las lesiones apicales no siempre alcanzan a la calcificación

Como ya lo hemos dicho más adelanté, hoy dia se acep ta por la gran mayoría de los autores, el origen endógeno de las formas de reinfección. La base de estas ideas está en los trabajos de Loomis, Pizzini y Lidia Rabinovistch, que comprueban gérmenes virulentos en ganglios tuberculosos obtenidos de individuos muertos por afecciones no tuberculosas; pero si se analizan los resultados obtenidos por todos los autores que se han ocupado de esta materia, tenemos un $51 \%$ de casos negativos, tomando en consideración las lesiones oulmonares y ganglionares. En lesiones calcificadas este porcentaje de negativijad llega a un $82 \%$, y en las fibrosas a un $85 \%$. El estudio de las lesiones apicales demuestra que hay una proporción de un $51 \%$ de negatividad en procesos ca seosos, en los calcificados de un $82 \%$ y en los fibrosos, dz un $85 \%$. Estas investigaciones se han hecho tanto en alul. tos como en niños.

De estos rrabajos se deduce:

1. Que la esterilización se produce tanto en lesionas pulmonares como ganglionates en un plazo de 2 a 5 años.

2. Las lesiones estudiadas han sido tanto de primo como de reinfección. lo que demuestra que la esterilización se produce en todas las etapas de la infección tuberculosa.

3. Queda un $20 \%$ de lesiones que no se esterilizan. aún cuando thayan alcanzado a una cicatrización avanzada.

De un modo general puede decirse que la esterilización de las lesiones tuberculosas. aún las caseosas, se hace más o menos rápidamente, para hacerse casi completa en el período de calcificación (4 casos sobre 5). Si consideramos ahora que la caleificación se opera entre 2 y 5 años y que las lesiones de primo-infección se adquieren thabitualmente antes de los 20 años, mientras qui las formas de reinfección comienzan a ser frecuentes después de los 30 años. se ve que es imposible que las formas de reinfección sean producidas por bacilos provenientes de la tuberculosis ptimaria. 
Estas investigaciones vendrían a aclarar un antiguo problema relativo a ciertas formas de tuberculosis primaria de origen bovino. Como se sabe, este tipo de bacilo se encuentra en forma casi exclusiva en la tuberculosis infantil: pero desaparece en las lesiones del adulto en las que se comprueba solamente el tipo humano. Si la tuberculosis del adulto'fuera la consecuencia de infección endógena provenientes de antiguas lesiones de primo-infección, no se explicaría este hecho paradojal, tanto más si consideramos que la mutación de una a otra forma de bacilo no es aceptada por los bacteriólogos. A la luz de los nuevos conceptos analizados podemos explicar fácilmente este hecho: la tuberculosis primaria se debería en muchos casos al bacilo bovino (ingestión be leche cruda). estas lesiones curarian clínica y bacteriológicamente en un plazo de 2 a 5 años, como hemos dicho mas atriba. Ahora bien, la aparición dal bacilo humano en las formas del adulto se explicaría por reinfecciones exógenas proverientes del medio infectado en que vive habitualment: el individuo adulto.

Referente a la inmunidad de sobre-infección. Ameuille y sus colaborajores consideran, desde el punto de vista expe. rimental, que ésta no es considerable sino en los animales quz tienen una tulberculosis evolutiva, que es débil en los animales con tuberculosis curada y que es tanto más débil cuanto menos virulentas es la cepa con que se ha hecho la primo-infección. En todo caso, la inmunidad de sobre infección no basta para impedir la entrada de infecciones masivas ni para evitar la diseminación a otros órganos.

Reinfección tuberculasa y sensibilidad tuberculina.-Como ya lo hemos dicho, se admite que li senuibilidad tuberculínica provocada por la primo-infección se mantiene durante toda la vida gracias a uno o más focos tuberculosos activos en el organismo; pero si consideramos que la esterilización de las lesiones se hace en un gran porcentaje de casos en un plazo de 2 a 5 años, no podemos concebir este mecanismo de man. tención de la alergia. Por otra parte, sabemos que en los animales que logran curar bacteriológicamente de la tuberculosis desaparece la sensibilidad tuberculínica (Calmette, Guerin y Bruno Laingue).

En la especie humana las observaciones sobre desaparición de la sensibilidad tuberculínica son inumerosas, como asi mismo las disminuciones en su intersidad. La persistencia de la sensibilidad tuberculinica durante toda la vida se deberia, según los autores que comentamos, a reinfecciones exógenas 
sucesivas, en individuos que viven en un medio altamente infectado.

La importancia práctica de los hechos que hemos expuesto es enorme, porque nos pone de manifiesto la preponderancia de la infécción tuberculosa sobre la enfermedad tuberculosa. Queda de manifesto, por otra parte, la curabilidad de la tuberculosis en forma expontánea en un gran número de individuos expuestos a reinfeccion s frecuentes hasta una edad avanzada. Los conceptos sobre la inmunidad de sobreinfección sostenidos hasta hoy dia no rienen una base firme de observación, porque, como hemos visto, pueden producirse reinfecciones exógenas con mucha frecuencia sin que esta inmunidad intervenga. Además a lả luz de los nuevos conceptos analizados, existiría en muchos casos períodos más o menos largos en que la alergia disminuiría o se pendería totalmente por la esterilización de las lesiones, dejando al organismo indefenso contra nuevas infecciones exógenas. Los autores vuelven a destacar la importancia de la inmunidad natural del organismo frente al bacilo de Koch como el medio más segaro de defensa contra la tuberculosis sin que llegnen a negar la inmunidad específica que sería en todo caso muy ralativa y que podria perderse en muchas ocasiones.

Estas mismas investigaciones vendrían a plancear nuevos aspectos referentes a la distribución de enfermos en los Sanatorios y a las posibilidades de reinfecciones graves entre el personal dedicado a la atención de en'fermos de tuberculosis.

Por último habria que considerar, a la luz de estas nuevas adquisiciones, los fundamentos de la vacunación por el $\mathrm{B}$ C. G., que está basada, como sabemos, con la inmunidad específica que adquiriría el organismo que ba sido infectado por el bacilo de Koch. ceda).

(Traducción y recopilación del Dr. Jorge Peña Cere- 